\title{
Ecological engineering of small urban water bodies
}

\author{
Antonina Suzdaleva ${ }^{1 *}$, Anna Hirsch $^{2}$, Maria Kuchkina ${ }^{2}$ \\ ${ }^{1}$ Moscow State University of Civil Engineering, 26, Yaroslavskoye Shosse, 129337, Moscow, Russia \\ ${ }^{2}$ LLC “Alfamed 2000" 105523, 50-55, 15-th Parkovaya Street, Moscow, Russia
}

\begin{abstract}
The ecological and sanitary epidemiological condition of small urban water bodies is an important factor in ensuring safety in urbanized areas of the technosphere. All modern small urban water bodies are naturaltechnical systems that can be uncontrollable or controllable. In managed natural-technical systems, favorable environmental conditions are formed as a result of the operation of special engineering devices and systems called ecological regulators. Their creation and ensuring sustainable existence are the main goal of ecological engineering of small urban water bodiesThe choice of a strategy for the environmental engineering of water bodies should be determined on the basis of a prognostic assessment of the possibility of improving or maintaining its positive functions: videoecological, recreational, biotopical potential, and also cultural, historical or religious significance. In addition, it is necessary to take into account public opinion, which can be changed by disseminating positive information about the goals of the proposed activity (active ecological image-making). The issue of organizing long-term technical maintenance of ecological regulators and monitoring of natural-technical systems of water bodies is being considered. The paper provides a classification of small urban water bodies and a generalized scheme of their ecological engineering. The necessity of an interdisciplinary approach to decision making and the development of syncretic thinking in this area is substantiated.
\end{abstract}

\section{Introduction}

The generally accepted definition of the term "small urban water body (SUWB)" does not yet exist. At the same time, it is often used both in scientific literature and in official documents, as well as concepts that are close in meaning (city pond, etc.). The SUWB category includes a wide range of objects of various origins and purposes [1]. It may be a small lake located in a city park, once a former forest site. At the same time, the SUWB can be considered both a pool with a fountain in the city square, and a drainage channel that permeates urban development. However, the territories of many cities include large water bodies or sections of their water areas. The methods used to maintain their favorable ecological status and its improvement are fundamentally different from measures taken with similar goals with respect to the SUWB. (For example, it is impossible to organize washing

\footnotetext{
* Corresponding author: suzdalevaal@yandex.ru
} 
of a large lake with clean water). At the same time, the boundary between small and large urban water bodies is conditional. Unsuitable for practical work and classification, used to scale natural water courses and reservoirs. So, according to paragraph 27 of the Russian State Standard GOST 19179-73 "Hydrology of land. Terms and definitions", a small river is a watercourse, the basin of which is located in one geographical area and has an area of not more than $2000 \mathrm{~km}^{2}$. There can be only a small segment of such a river on the territory of the city, and the management of its ecological state is beyond the powers of city services. In addition, the real drainage basin of the river in urban areas is determined not so much by the relief as by the features of the surface drainage system. Thus, the development of methods of practical work with the SUWB requires the clarification of this concept.

Based on an analysis of the literature and our own experience in developing improvement projects for such objects [2-4], we can give the following general definition: SUWB is any water body (lake, pond, pool) or water course (river, stream, channel) partially or completely located in urban areas, the dimensions of which are comparable to the main elements of urban development (buildings, structures, transport highways).

The state of the SUWB is determined by the nature of the urbanization of the environment. For example, the quality of the aquatic environment in ponds located on the territory of industrial zones, as a rule, differs notably from the quality of the water of ponds in the center of a large park. But in each of these water bodies, there is always a complex of living organisms. They are not always noticeable to urban residents, but they are able to make both a positive and negative impact on them.

The nature of the impact of the SUWB on the population of a modern city is determined by a set of technical factors due to the attitude of the population and city authorities to the water body. Disregarded water bodies accumulate pollutants and then release harmful substances into the air. They can become a source of infections and their vectors. However, with the help of technical measures, it is possible to maintain the SUWB in the form that improves the urban climate and has a beneficial effect on the emotional state of a person. Thus, all SUWBs are natural-technical systems, which can be uncontrollable and controllable [5]. In managed natural-technical systems, favorable environmental conditions are formed as a result of the operation of special engineering devices and systems called ecological regulators. Their example is closed water circulation systems in some Moscow ponds [6].

At the same time, the use of engineering and technical means to improve the state of the SUWB not always gives the desired results. The main reasons for the failures in this area are the ignoring of the specific features of the various types of SUWBs and miscalculations in the planning of their existence. Therefore, the taken actions often give only a temporary effect, after which the repeated degradation of the SUWB begins. The study of these problems is the main purpose of this paper. The ideas and practical suggestions put forward in it are based on the experience gained during the development of projects to improve the ecological status of various SUWBs in Moscow and the Moscow Region.

\section{Environmental-engineering technogenesis}

Nowadays, there are two different approaches to environmental protection. The first is various traditional environmental measures - from pollution control to the construction of special protective structures. Despite the fact that the goal of this activity is to preserve the natural environment, its implementation almost always represents the beginning of the transformation of a protected natural object into a natural and natural-technical system. Its condition is determined not by the natural mechanisms of self-regulation, but by targeted human actions. The operational control of the environment and the prevention of its pollution requires the "integration" of special engineering and technical infrastructure (environmental management) into this environment, the functioning of which becomes a significant factor 
regulating (preventing) environmental degradation. The development of human civilization is accompanied by a constant increase in anthropogenic impact on the environment. In this situation, the preservation of favorable (or at least acceptable) environmental conditions can be provided by only an adequate strengthening of engineering measures to protect it. Thus, paradoxically as it sounds, the development of the environmental protection system is nothing more than the development of one of the forms of its technogenesis, namely, environmental-engineering technogenesis. Based on the amount of necessary financial costs, modern society can carry out such activities only at the local level, maintaining the favorable condition of the natural-technical system, which has small scales (environmental-engineering of small urban water bodies). The creation of special engineering systems designed to regulate environmental conditions at the regional and, especially, interregional levels is unrealistic. Therefore, the second way, which is to endow these functions with existing largescale engineering systems, is becoming increasingly important. Existing water systems are most suitable for this purpose. Large hydropower plants and their cascades are playing an increasingly important role in environmental regulation. Thus, in this case, it is rather a matter of giving a systemic character to these aspects of their activities and recognizing their role in ensuring ecological safety and human life safety across large regions. These actions are denoted by the term "ecological optimization", which means the modernization of the operating mode of technical facilities and engineering systems, as well as their structural and design features enhancing the importance of the positive aspects of technogenesis while reducing negative ones. The end result of ecological optimization is the formation of a managed natural-technical system in which an ecological optimized engineering and technical object (or their coordinated group) acts as its regulator.

\section{Forms and main types of ecological engineering of SUWB}

Initially, the term "engineering" (ingenium (latin) - to create, make, invent) meant the use of intellectual abilities to solve practical problems. Nowadays, in the most general sense, this concept means the application of scientific methods and tools for the development, creation and use of artificial systems or for interfering with the development of natural systems in order to solve problems in various subject areas (Rybets, 2011).

The ecological engineering of SUWB is the development and implementation of a system of scientifically sound methods for the long-term management of the state of these facilities, which ensure that they perform their basic functions as an element of the urban environment. Ecological engineering can take two forms. The first of these is eco-design or the development of environmentally-oriented projects for the improvement of SUWB. The second is the provision of consulting services to maintain a favorable environmental situation in the areas where these facilities are located and to improve it (ecological consulting).

The fundamental goal of the ecological engineering of SUWB is to ensure their sustainable existence in the form of managed natural-technical systems. In general theoretical terms, this activity is based on the basic principles of system technoecology [6]:

1. Pragmatism in solving the problems of maintaining a favorable environment (ecological realism). The ecological engineering of SUWB should be aimed at creating and maintaining the most favorable environmental situation, the possible framework of existing realities (i.e. by creating a managed natural-technical system), and not at futile attempts to recreate the SUWB as a natural ecosystem at any cost.

2. The priority of preventive solutions to ecological problems, based on an analysis of the existing risks of environmental degradation. When creating managed natural-technical systems in urban areas, compliance with this principle can be considered as ensuring ecological safety in these areas of the technosphere. 
3. An interdisciplinary approach, which implies the effective joint work of specialists with technical and bioecological education.

4. The syncretism of thinking when creating controllable NMMSs is the ability to work out compromises and optimal solutions in the existing conditions on the basis of a reasonable comparison of people's positions with different worldviews ("technocrats" and "environmentalists").

5. The hierarchical structure of managed natural-technical systems. This principle consists in the fact that when studying (designing) any natural-technical systems, it is necessary to take into account that it is (or can become) an element of a natural-technical systems of a higher rank or, on the contrary, its elements can in some cases be simultaneously considered as a natural-technical systems of a lower rank. So, with the ecological engineering of SUWB, it is necessary to assess its role in the hydrographic network of the city.

In practice, the nature of the specific tasks performed during ecological engineering is very different. For example, it could be a reconstruction of the lost SUWBs. However, some SUWBs pose a threat to the population. They can spontaneously arise as technogenic formations, for example, as a result of accumulation of water in abandoned pits in the territories of industrial zones. Their existence worsens the environmental and sanitaryepidemiological situation in the city, creates a direct danger to people, especially for children. For this reason, the ecological engineering of SUWB also includes the development of measures to limit and prevent their negative impact, and, if necessary, the development of projects to eliminate such facilities.

The diversity of the goals of the ecological engineering of SUWB has led to the emergence of various types of this activity. The main ones are [4, 8]:

- protection of the SUWB - measures to prevent external negative influences. These include, for example, the discharge of polluted surface runoff water flowing into the SUWB to a sewage treatment plant;

- conservation of the SUWB - a set of measures aimed at preserving the appearance of a water body existing at a given time. This type of activity includes measures to maintain sanitary and hygienic indicators and preventive repair work of hydraulic structures that ensure the existence of this facility (dams, locks, etc.). As a rule, the preservation of the SUWB is carried out when its historical reconstruction or restoration at a given time is impossible or inexpedient for economic or social reasons;

- rehabilitation (engineering and technical reconstruction) of the SUWB is the activity of returning degraded water bodies (or their isolated sections) to a safe ecological state. Some rehabilitation projects include the SUWB's ecological reanimation activities, i.e. the introduction of aquatic animals and plants, giving these objects additional social attractiveness;

- restoration of the SUWB - ecological engineering, the purpose of which is to give the water body the look typical of it in a particular historical era. Restoration can be carried out only in case of the availability of historical documents confirming the architectural and compositional appearance of the water body. In contrast to rehabilitation, restoration includes the restoration of buildings, hydraulic structures, park design elements that form the historical appearance of a given water body;

- historical reconstruction of the SWUB - engineering measures, the purpose of which is to adapt the water body to modern conditions while preserving its valuable historical or memorial elements. The main goal of this form of ecological engineering is to preserve the so-called "genius loci" (spirit of the place) [9]. This concept, adopted in 2008 in the Quebec Declaration by the International Council on Monuments and Sites, in particular, means material objects that give the territory its individual character, meaning, emotionality and mystery. In contrast to restoration, when performing works on historical reconstruction, it is 
allowed to use analogues or techniques for the design of its compositions, characteristic for a certain period of existence (era) of this SUWB, which could be absent at that time;

- isolation of the SUWB - engineering and technical measures to reduce the harmful effects arising from it (for example, the spread of contaminated water through a hydrographic network), and restricting the access of the population to it;

- liquidation of the SUWB - a set of engineering and technical measures whose purpose is the destruction of an undesirable water reservoir or watercourse as a surface water body.

In practice, the choice of ecological engineering actions often causes certain difficulties. This is due to the fact that in addition to the ecological aspect of the problem, there are almost always a number of others: recreational, medical, cultural and historical, technical and operational, socio-psychological. Often, the interests of certain groups of the urban population, giving preference to one of these aspects, are rejected by others. So, people who use an unprepared water body for swimming can negatively relate to its restoration, which limits the possibility of free use of the water body as a place of mass recreation.

\section{The functions of SUWBs in modern cities, their classification and ecological engineering strategy}

The ecological engineering of the SUWB is carried out with the aim of increasing the comfort of living conditions of the urban population. The success of this activity is determined by the degree of positive perception of the results by people. At the same time, a scientifically sound choice of an ecological engineering strategy, i.e. its main purpose and the types of activity applicable to its achievement, cannot be based solely on public opinion. Lacking completeness of information and lacking special knowledge, people may misrepresent the possible consequences of a particular type of ecological engineering. Its strategy should be determined by specialists on the basis of an analysis of the functions performed by these facilities and the needs of the population associated with them. These include participation in creating the image of the city, its social attractiveness. This factor determines not only the aesthetics of the urban area, but also has a significant impact on people's health. This led to the emergence of a special scientific discipline "video ecology" [10]. The ability of SUWB to significantly improve or worsen the perception of an urban area can be described as its "videoecological potential" [4]. It is formed not only by the view of the water body itself. An important role is played by plants and animals living in it or near it, for example, waterfowl. Such an important function of the SUWB as the preservation and creation of habitats (biotopes) for representatives of urban flora and fauna is directly connected with this. Improving the state of the SUWB contributes to the emergence of new species in it, the growth of the biodiversity of its territory. This function can be described as the growth of "biotopical potential".

Around many SUWBs at all times, sites were formed that served for mass recreation of the population - "urban resorts" [11]. With the growth of cities, the people living in them are increasingly demanding outdoor recreation, which most of them understand not as "wild" areas with natural ecosystems, but areas with elements of the natural environment located in their places of residence. The most important of these elements is SUWBs, or rather their "recreational potential" - the ability to create comfortable conditions for people to relax.

Some SUWBs are important elements of the historical part of urban development or are of cult significance.

Thus, the choice of the SUWB ecological engineering strategy should be determined on the basis of a prognostic assessment of the possibility of improving (maintaining) at least one of its modern functions - videoecological, recreational, biotopical potential, as well as cultural, historical or religious significance. 
The SUWB ecological engineering strategy in many respects depends on their existing state, the "starting one" from the point of view of developing and implementing projects to improve it. To assess it, a classification of objects is necessary, which allows them to be distinguished into separate categories, each of which has its own specifics. For example, in developing an ecological 1 engineering strategy, the SUWB can be classified as follows [4]:

1. Completely lost water body. This category includes objects whose restoration in modern urban conditions is unrealistic. The need to include this category is caused by the fact that, in some cases, the ecological engineering of SUWB carried out in the form of a consulting service requires the development of a scientifically based decision on the fundamental possibility or impossibility of reconstructing a water body.

2. Temporarily lost water body. This category includes objects that are currently almost non-existent, but are subject to restoration through the implementation of rehabilitation projects, historical reconstruction, and restoration (Fig. 1).

3. Fragmentedly preserved water body. This type includes urban rivers, almost completely flowing through underground pipelines. Their small areas remained open. As a rule, they are heavily polluted and unattractive (Fig. 2). Recreating these rivers is impossible. At the same time, their individual fragments, for example, preserved within the park areas, can be turned into the SUWB, which have high videoecological and recreational potential [12]. For this, it is necessary to conduct the following engineering, irrigation, drainage and ecological measures:

- isolation of the restored fragment of the river channel from the flow of contaminated water coming from a closed section of the river by diverting it to the city storm sewage system;

- rehabilitation of an isolated fragment of the channel by cleaning from sediment and filling it with clean water from another source, as well as creating a system of artificial circulation and water purification;

- ecological reanimation, i.e. the formation of the biotical complex of the SUWB (creation of thickets of coastal vegetation, etc.).

A similar object creates the illusion of a "clean river" section. In this regard, to designate such SUWB, the term "imitation water bodies" can be used.

4. Recreationally insignificant water body. This category includes SUWBs that do not have recreational potential, i.e. their shores are not used by the population as recreation areas (Fig. 3). Ecological engineering of recreationally insignificant SUWBs can be carried out in the form of their rehabilitation. In those cases where such water bodies constitute a danger to public health, and it is impossible or inappropriate to carry out measures to improve their condition, their ecological engineering consists in developing projects for their isolation or liquidation.

5. Water body of a low recreational significance - SUWB which due to lack of infrastructure and poor ecological and sanitary conditions is not officially a city resort (Fig. 4). The presence of such facilities in the urban area also does not improve the videoecological situation. At the same time, the population uses the coastal zone, and sometimes the water body itself, as a resting place, sometimes even a popular one. The spontaneous formation of such "unorganized resorts" [11] often poses a danger to human health. But at the same time, such areas (for example, undeveloped floodplains of city rivers) are the habitat of various species of animals and plants. For this reason, the strategy of ecological engineering of SUWB of a low recreational significance usually consists in their rehabilitation, taking into account the possibility of preserving their biotopical potential. 


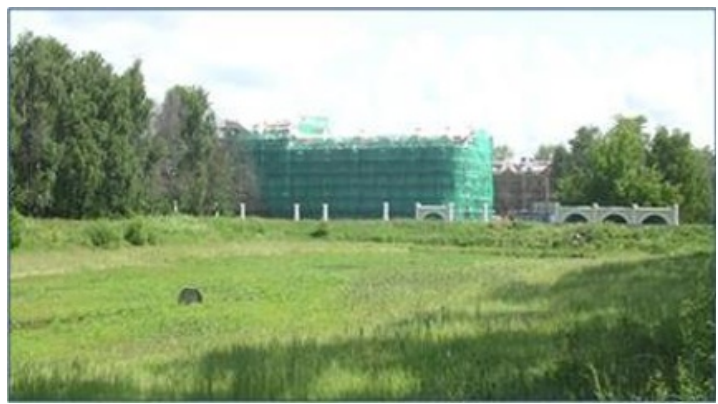

Fig. 1. Temporarily lost water body (Nizhnie Meshcherskie Ponds, Moscow).

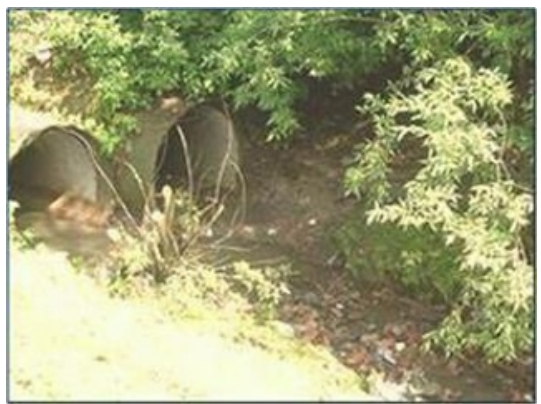

Fig. 2. Fragmentedly preserved water body (ZHuzha River, Moscow).

6. Recreationally significant water body, i.e. SUWB which is a backbone element of the "organized resort" [11], which has a special infrastructure that provides comfortable and safe conditions for mass recreation of the urban population. In addition to a high recreational potential, such a SUWB must have a satisfactory sanitary and hygienic condition, and, as a rule, significant videoecological, and sometimes biotopical potential. However, the positive functional role of recreationally significant water bodies is not a reason to exclude them from the field of ecological engineering. On the contrary, as practice shows, most of the recreationally important SUWBs quickly degrade without the systematic implementation of special measures (protection and periodic rehabilitation).

7. Historically valuable SUWB, i.e. which is an object of cultural and historical heritage (Fig. 5). The current environmental and sanitary-hygienic state of such facilities may be different, including unsatisfactory. A feature of ecological engineering in this case is that their goal is not rehabilitation, but historical reconstruction or even restoration of a water body.

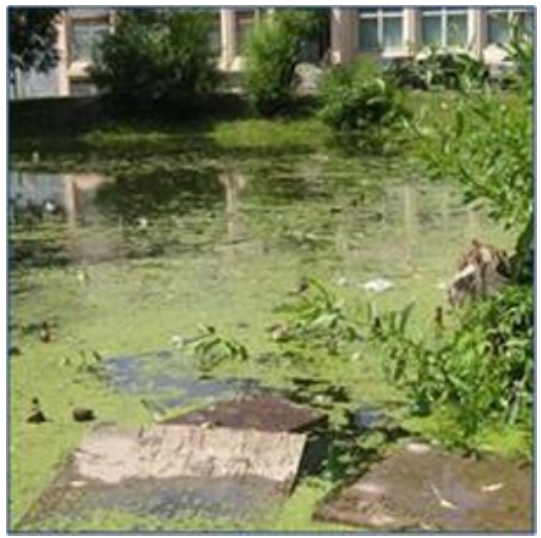

Fig. 3. Recreationally insignificant water body (Pond on Feodosijskaya street, Moscow).

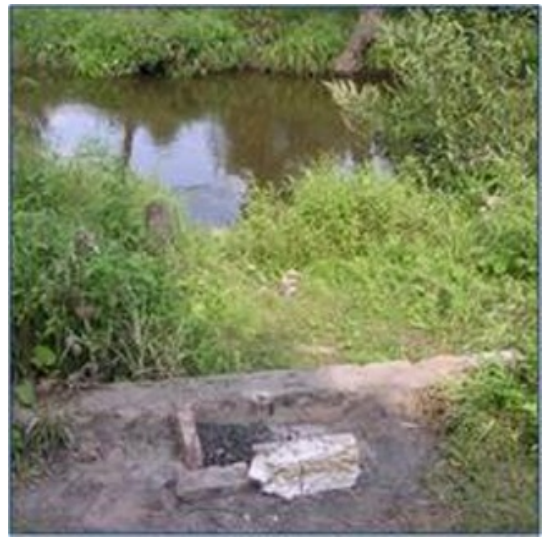

Fig. 4. Water body of a low recreational significance (Lihoborka River, Moscow). 


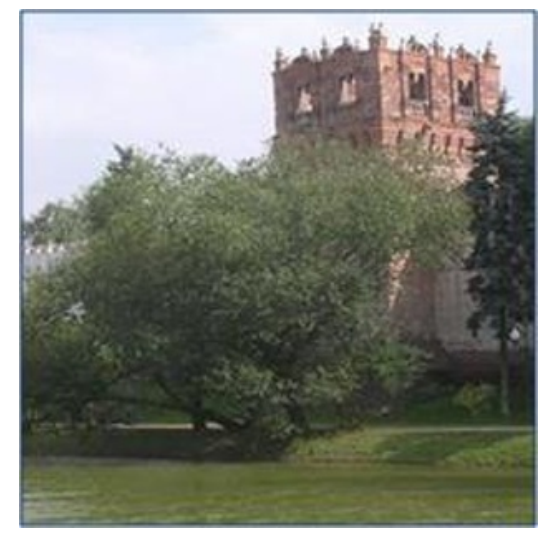

Fig. 5. Historically valuable small urban water body (Pond of the Novodevichy Convent, Moscow).

8. SUWB of cult significance. The specificity of its ecological engineering is the careful consideration of religious beliefs about it. Any projects aimed at improving its ecological condition, videoecological and recreational potential should be agreed in advance with representatives of the respective religious communities.

\section{Stages of ecological engineering of SUWB and its generalized scheme}

The ecological engineering of SUWB can only have a sustainable effect if it is systemic in nature. Its consistency lies in the allocation of individual stages or phases, the ongoing activities pursue their tasks and unification in the framework of achieving a common goal. When conducting ecological engineering in the form of eco-design, this increases the validity and effectiveness of the design decisions. In the case of ecological consulting, a systematic approach allows developing recommendations to optimize work planning based on the specification of its tasks at each stage and the sequence of their solutions. The main of these stages are:

1. Development of a historical prototype of a SUWB. At the initial stage of ecological engineering, as a rule, the question arises about the desired appearance of the object. Usually, the basis is the appearance of the city water reservoir or watercourse characteristic for one or another historical period, including modern styles of designing such objects. This appearance, which creates in the minds of people a certain perception of a SUWB (its image), is designated as a "historical prototype" [4]. This concept can be not only individual in nature (for example, Patriarch's Ponds in Moscow), but also categorical (for example, SUWB decorated in the style of suburban estates of the early 19th century). The degree of historical certainty of this appearance may vary. When developing a rehabilitation project, there can only be some external features characteristic for the SUWB of a certain era (for example, a characteristic coastal lining). In this case, the main goal of creating a historical prototype is to define the "architectural style of the SUWB", i.e. ways of designing its appearance (Fig. 6-7).

In the case of a historical reconstruction project, this is the restoration of certain details of the historical appearance of the water body, creating the "genius loci" of a certain era. This requires a more complete correspondence between the appearance of the SUWB and its surrounding area. In this case, significant discrepancies with real pre-existing conditions are also possible. In contrast, the historical prototype in the development of restoration projects should have a significant degree of reliability. 
It should be emphasized that in all of the above options for creating a historical prototype, we are talking only about choosing the external appearance of the SUWB, rather than restoring the ecological state of a water body that existed in the same historical era. In the vast majority of cases, the latter is almost impossible due to the irreversible transformation of the drainage basin. In some cases, this is undesirable. In the past, many SUWBs were a threat to the population from a sanitary epidemiological point of view.

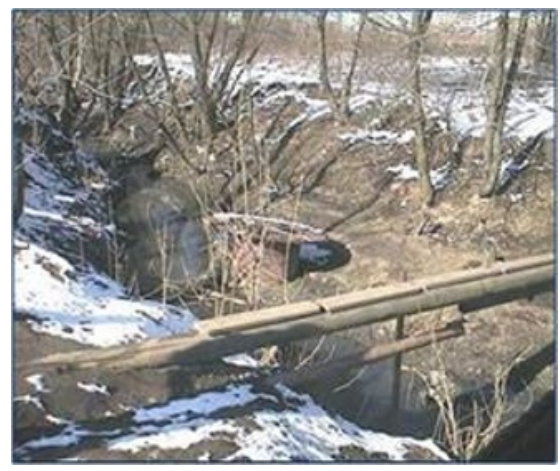

Fig. 6. Zhuzha River before rehabilitation project (2005).
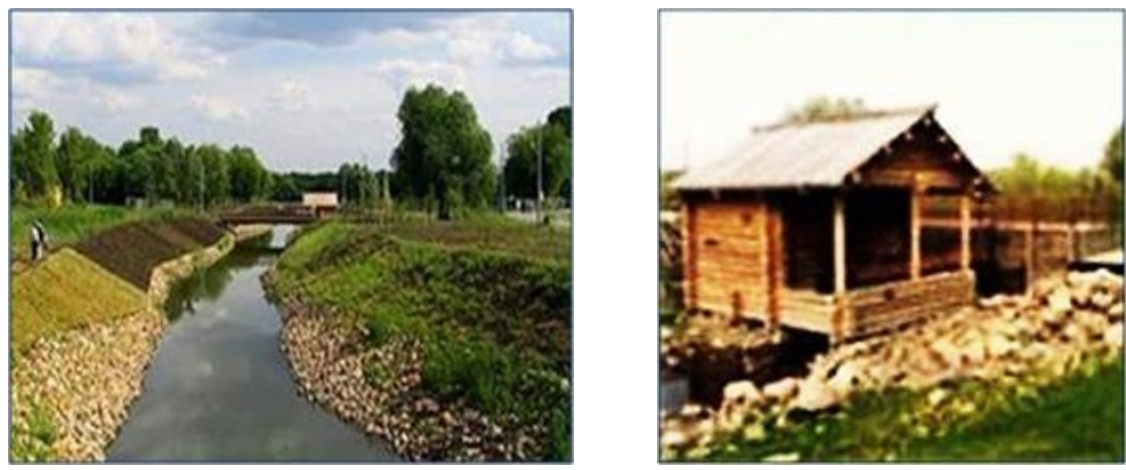

Fig. 7. Creation of a determined architectural style: coastal lining, river dam and water mill on the the Zhuzha River (2016).

2. Development of a history-ecological prototype of a SUWB. In the conditions of a modern city, the intensity of the self-cleaning and self-healing processes of SUWBs is not comparable with the number of pollutants entering them. The provision of a good (or at least acceptable) ecological and sanitary-hygienic condition is possible only thanks to the work of special engineering devices - ecological regulators, the presence of which turns the SUWB into a controllable managed natural-technical system.

An important task is the incorporation of biological objects that enhance the videoecological and recreational potential of the SUWB into this natural-technical system. Deprived of noticeable signs of life, the water body creates a repulsive impression. A negative reaction is caused by objects overgrown with unattractive aquatic vegetation, for example, covered with slime. To solve this problem, plans are being developed for the ecological reanimation of SUWBs, i.e. purposeful introduction of various organisms into the water body, the presence of which is noticeable in it and causes positive emotions in people. The main problem in this case is the formation of a stable complex from these animals and plants. 
As a rule, this involves the introduction of additional systematic measures in ecological engineering plans, for example, feeding waterfowl and removing excess aquatic vegetation.

Thus, this stage of ecological engineering consists in designing a controllable natural and managed natural-technical system based on a compromise solution of ecological, sanitary epidemiological, historical, recreational, video-ecological and engineering problems. The result of this work can be described by the term "history-ecological prototype of a SUWB" [4], implying a set of ideas about the external appearance of this object and the methods of its formation under existing conditions.

3 . The development of the ecological-legal justification for the ecological engineering of SUWB means to determine its legal status, as well as the status of the surrounding territory, which is affected by the proposed activity. In addition, an important task is to identify potential stakeholders, i.e. individuals and legal entities that can affect the implementation of the project or experience its consequences. For convenience of analysis, it is advisable to divide them into several functional groups [13]. This activity should be carried out proactively, i.e. ahead of the implementation of the ecological engineering prototype of SUWB. Otherwise, as practice shows, legal obstacles may arise that require a fundamental revision of an already completed project or even a refusal to implement it.

4. Consideration of public opinion and work on the formation of a positive image of SUWB. Views on the functions of the projected object can significantly differ for its creators and the urban population. Especially dangerous is the underestimation of this factor when trying to introduce foreign experience. So, on the basis of some small ponds located in the territory of Moscow, attempts were made to organize paid recreational fishing facilities, including their periodic stocking [14]. Similar projects have been very successfully implemented in some European countries. However, in Russia, this idea, according to polls, did not find mass support among fishermen. According to them, despite a number of amenities (walking distance, equipped fishing spots), catching the same type of fish (carp) just released into the pond from the cage does not bring pleasure like fishing in a natural water body with its unpredictable results.

Of particular importance is the inclusion of public opinion in the ecological engineering of SUWBs, which has religious, cult or cultural and historical significance.

At the same time, public opinion can be changed by actively introducing a positive image of the planned activity into the consciousness of the urban population. The methods of active ecological image-making used for this do not fundamentally differ from similar actions when working with other projects [13].

5. Development of a program for engineering-ecological monitoring of SUWBs during their operation. Many failures in the field of ecological engineering of these facilities were caused by ignoring the problem of maintaining their condition at the end of the project. As a rule, the organization, having completed the work envisaged by the SUWB's eco-design project, does not show interest in its further fate. At the same time, ecological regulators of the created natural-technical system need maintenance and periodic repair. If the organization responsible for the condition of SUWB does not have the necessary specialists and necessary means for this, then the achieved results will be lost. Therefore, systemic ecological engineering should include actions to control the operation of ecological regulators and monitor the state of the created natural and man-made system. This activity can be carried out in various forms, for example, in assigning this obligation to municipal authorities. But the most optimal, from the point of view of sustainable ensuring the favorable state of the SUWB, is the organization of a city-wide specialized service, the tasks of which simultaneously include monitoring these objects and servicing their ecological regulators. The main task of ecological engineering in this case is reduced to consulting services, i.e. developing recommendations for improving the work of such services. 


\section{Conclusion}

1. Sustainable maintenance of the safe state of SUWBs under modern conditions is possible only on the basis of their transformation into managed natural-technical system systems.

2. The success of the ecological engineering of the SUWB can be achieved only with a systematic approach to its organization based on the generalized scheme considered in the paper. The necessary conditions for this are an interdisciplinary approach to decision making and the syncretism of the thinking of specialists in various fields.

3. The strategy of ecological engineering of SUWBs should be determined on the basis of an analysis of their functions, both existing and hypothetical, assessed taking into account public opinion.

\section{References}

1. V.N. Beznosov, S.V. Goryunova, E.L. Kolesnikova, A.A. Hirsch (Suzdaleva) Bulletin of Peoples' Friendship University of Russia. Series "Ecology and life safety" 2(14), 3642 (2006)

2. A.A. Suzdaleva, S.V. Goryunova, Collection of scientific proceedings "Actual problems of ecology and nature management" (Publishing House of Peoples' Friendship University of Russia, 2004)

3. A.A. Suzdaleva, Electronics, electrical engineering and energy. 11th International scientific and technical conference of undergraduate and graduate students 2 (MPEI, Moscow, 2005)

4. A.A. Suzdaleva, Ecological engineering and ways to increase the recreational potential of small urban water bodies. Extended abstract of dissertation of PhD in Engineering (Moscow State University of Civil Engineering, Moscow, 2005)

5. A.L. Suzdaleva, Creation of managed natural-technical systems (ID ENERGY, Moscow, 2016)

6. V.V. Volshanik, A.A. Suzdaleva, Classification of urban water bodies (Publishing House of the Association of Construction Universities, 2008)

7. A.L. Suzdaleva, Safety in Technosphere 5(3), 6-14 (2016)

8. V.N. Beznosov, V.B. Rodionov, A.A. Suzdaleva, E.L. Kolesnikova, Safety of energy facilities 16, 216-228 (2007)

9. N.E. Antonova, Architecture 1, 30-38 (2015)

10. V.A. Filin, Videoecology. What is good for the eye and what is bad (MC "Videoecology", Moscow, 1997)

11. A.L. Suzdaleva, V.N. Beznosov, A.A. Suzdaleva, Ecology of Urban Areas 3, 29-34 (2012)

12. A.A. Suzdaleva, Water ecosystems and organisms. Proceedings of scientific conference (MAKS-Press, Moscow, 2006)

13. A.L. Suzdaleva, The formation of the environmental image of the industrial organization and their products (ID ENERGIYA, Moscow, 2016)

14. A.L. Suzdaleva, V.N. Beznosov, Ecology and the development of society 1(3), 23-27 (2012) 